ment, and a revision of dosage then becomes necessary. Modification of dosage in renal failure is more practical for routine hospital use if only the interval between doses is altered as outlined in Table III. It is, however, feasible to use a smaller dose of 60 or $40 \mathrm{mg}$. at more frequent intervals after the initial loading dose of $80 \mathrm{mg}$. to maintain a therapeutic serum level.

In only one instance have there been any observed toxic sideeffects. These occurred in a woman (Case 9, Table I) who one hour after a single $80-\mathrm{mg}$. injection complained of marked giddiness. The symptoms were associated with a peak serum level of $12 \mu \mathrm{g} . / \mathrm{ml}$., the highest in the series, and persisted for one and a half hours. We have not administered gentamicin on a body-weight basis but have used the more simple and practical method of giving $80 \mathrm{mg}$. (2-ml. phial) at suitable intervals, depending on renal function. There is, however, a negative correlation between body weight and peak serum level in the patients studied which is statistically significant at the $5 \%$ level. In view of the high peak level attained in the one subject described, who weighed only $46.5 \mathrm{~kg}$., we now use a $60-\mathrm{mg}$. dose in patients weighing less than $60 \mathrm{~kg}$.

The present study is part of a clinical investigation of gentamicin in resistant urinary tract infections, including Ps. aeruginosa, which is still in progress. This study includes pretreatment and post-treatment vestibulometry to assess toxicity, and to date there have been no recorded untoward sequelae of treatment with the increased dose regimen described.

\section{Summary}

Serum levels of gentamicin have been determined in normal subjects and in patients with renal impairment after $80 \mathrm{mg}$. intramuscularly. The average peak serum level obtained was $7.0 \mu \mathrm{g} . / \mathrm{ml}$., which is independent of renal function, assessed by endogenous creatinine clearance. In the presence of normal renal function there was a rapid fall in the serum level to approximately $1 \mu \mathrm{g} . / \mathrm{ml}$. at eight hours, and it is advised that gentamicin be given at eight-hourly intervals. The glomerular filtration rate (endogenous creatinine clearance) and the serum half-life of gentamicin have been correlated in 18 subjects. This has enabled the formulation of a dose schedule in patients with impaired renal function based on the glomerular filtration rate. It is suggested that in renal failure the interval between doses should be lengthened, and an approximate scheme of dosage is presented.

ADDENDUM.-British Schering Limited, the suppliers of gentamicin, have recently recommended that the antibotic be administered eight-hourly and not 12-hourly to patients with normal renal function.

We are grateful to Professor L. P. Garrod for his advice in the conduct of this investigation and for his helpful criticism in the preparation of the paper. We wish also to thank Professor Ralph Shackman for permission to study these patients, who were under his care. The gentamicin was supplied by British Schering Limited.

\section{REFERENCES} Barber, Mary, and Waterworth, Pamela M. (1966). Brit. med. f., 1, 203.
Black, J., Calesnick, B., Williams, D., and Weinstein, M. J. (1963). Black, Jimicrobial Agents and Chemotherapy, p. 138.

Bulger, R. J., Sidell, S., and Kirby, W. M. M. (1963). Ann. intern. Med., 59, 593.

Chisholm, G. D., Calnan, J. S., Waterworth, P. M., and Reis, N. D. (1968). Brit. med. F. In press.

Curtis, J. R., McDonald, S. J., and Weston, J. H. (1967). Brit. med. f., 2, 537.

. (1967). Brit. med. F., 2, 535. Jao, R. L., and Jackson, G. G. (1964). 7. Amer. med. Ass., 189, 817 lein, J. O., Eickhoff, T. C., and Finland, M. (1964). Amer. F. med. Mitchison, 248, 528.

Mitchison, D. A., and Spicer, C. C. (1949). F. gen. Microbiol., 3, 184 (1963). Antimicrobial

Agents and Chemotherapy, p. 164.
Rubenis, Mary, Kozii, Vera M., and Jackson, G. G. (1963). Antimicrobial Agents and Chemotherapy, p. 153.

Sørenen, A. W. S., Szabo, L., Pedersen, A., and Scharff, A. (1967) Postgrad. med., f., 43, May Suppl., p. 37 .

Sweedler, D. R., Gravenkemper, C. F., Bulger, R. J., Brodie, Jean L. and Kirby, W. M. M. (1963). Antimicrobial Agents and Chemotherapy, p. 157.

Weinstein, M. J., Luedemann, G. M., Oden, E. M., and Wagman, G. H. (1963). Antimicrobial Agents and Chemotherapy, p. 1.

\title{
Distribution of Gentamicin in Body Fluids
}

\author{
G. D. CHISHOLM,* CH.M., F.R.C.S., F.R.C.S.ED. ; J. S. CALNAN, $\dagger$ M.R.C.P., F.R.C.S. \\ PAMELA M. WATERWORTH, $\ddagger$ F.I.M.L.T. ; N. D. REIS,§ F.R.C.S.
}

Brit. med. F., 1968, 2, 22-24

The clinical value of an antibiotic depends on an effective concentration reaching the sites of infection. A urinary infection may seem to respond to an antibiotic by its ability to sterilize the urine, yet chronic pyelonephritis may still develop in later years. Close follow-up is essential to detect a recurrence of the urinary infection (Garrod et al., 1954) even though there may be no symptoms referable to the urinary tract (Kleeman et al., 1960). This anomaly is generally explained by the failure of the antibiotic to treat foci of infection in the renal parenchyma effectively. The concentration of any antibiotic or chemotherapeutic agent in the renal parenchyma may therefore be of considerable importance in the assessment of its effectiveness in the treatment of urinary tract infection (Schlegel, 1962 ; Katz et al., 1964 ; Jameson, 1965).

\footnotetext{
* Consultant Urological Surgeon, Hammersmith Hospital and Royal Postgraduate Medical School, London $\mathbb{W} .12$.

t Reader in Plastic Surgery, Hammersmith Hospital and Royal Postgraduate Medical School, London W.12.

$\ddagger$ Research Assistant, Hammersmith Hospital and Royal Postgraduate Medical School, London W.12.

$\checkmark$ Research Fellow, Hammersmith Hospital and Royal Postgraduate Medical School, London W.12.
}

The clinical value of gentamicin in the treatment of a urinary tract infection has been shown in patients with either normal or impaired renal function (Bulger et al., 1963; Jao and Jackson, 1964). This antibiotic is of particular value against Pseudomonas aeruginosa and Proteus and resistant strains of Staphylococcus aureus (Barber and Waterworth, 1966). The present studies were made in order to measure the rate of distribution and excretion of gentamicin in the body fluids of the normal dog.

\section{Materials and Methods}

Fifteen greyhounds, each weighing 20-30 kg., were studied in two groups. When samples of blood and urine were required the unanaesthetized animal remained in a Pavlov stand. When lymph as well as blood and urine samples were required, the animal was anaesthetized with sodium pentobarbitone and maintained on oxygen and nitrous oxide. Lymph was obtained from the thoracic duct, which was exposed through a neck incision and cannulated with fine polyethylene tubing $(1 \mathrm{~mm}$. 
internal diameter). Lymph was also obtained from the left renal hilum, which was exposed through a flank incision and cannulated with a fine tapered nylon catheter $(0.5 \mathrm{~mm}$. internal diameter). In two of these studies samples of lymph were also obtained by cannulating one of the lymphatics lying beneath the renal capsule (Fig. 1).

Group 1. Studies on Rate of Distribution and Excretion of Gentamicin.-Dose response curves were obtained after a single intramuscular injection of $40 \mathrm{mg}$. Serial samples of blood, urine, and thoracic duct lymph were taken over a period

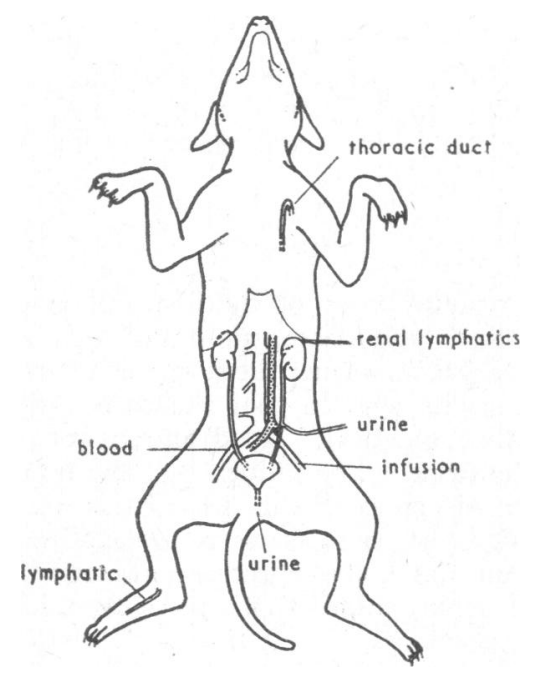

Fig. 1.-Basic preparation and sampling techniques.

of five hours. The concentration of gentamicin in the urine was studied in relation to variations in urine flow rate, which was altered by use of a diuretic ( $20 \%$ mannitol). The $p H$ of the urine samples was measured and then corrected to $\mathrm{pH} 8$.

Group 2. Studies in Concentration of Gentamicin in Renal Lymph. - The dose required to maintain a constant blood level was first determined and then was administered hourly so that, when collections of renal lymph were made-usually two and a half to three hours after the initial injection-it could be assumed that equilibrium between the antibiotic and body fluids had been achieved. It was found technically difficult to maintain a cannula in a lymphatic in the renal hilum for longer than 60 minutes. The flow from such a lymphatic rarely exceeded $0.2 \mathrm{ml}$. per minute. Three serial lymph samples were collected together with samples of venous blood, urine, and thoracic duct lymph taken at the midpoint of each hilar lymphatic collection. In two experiments samples of lymph from a capsular lymphatic were taken after the hilar lymphatic collection was completed.

The concentration of gentamicin in serum, urine, and lymph was determined by the vertical diffusion technique of Mitchison and Spicer (1949), the Oxford Staphylococcus being used.

\section{Results}

Group 1. Rate of Distribution and Excretion of Gentamicin. - Gentamicin was rapidly absorbed and the peak level in the serum was reached within 30 to 60 minutes of a single intramuscular injection of $40 \mathrm{mg}$. (Fig. 2). The peak levels for urine and thoracic duct lymph were also reached at approximately the same time. The rate of excretion from the dog was rapid and the serum level had fallen to half the peak value by two hours. Gentamicin levels in the thoracic duct lymph fell at a rate similar to that of the serum, and in all of these experiments the antibiotic had disappeared almost completely from serum and lymph five hours after the injection. In three drug- recovery studies, where urine was collected for five hours, the amount of drug recovered (after a $40-\mathrm{mg}$. dose) was $35 \mathrm{mg}$., $35 \mathrm{mg}$., and $46 \mathrm{mg}$. These differences were thought to be due to experimental error. It was noted during these experiments that the urine became progressively more alkaline, and since the assay of gentamicin is affected by the $\mathrm{pH}$ all samples were corrected to $\mathrm{pH} 8$.

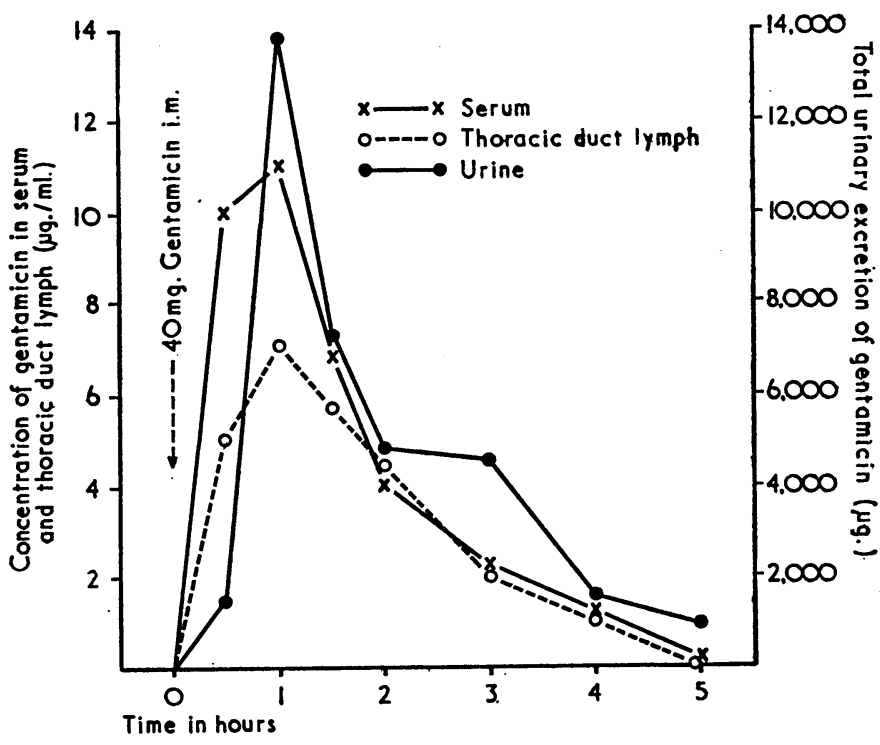

Fig. 2.-Rate of distribution into serum and thoracic duct lymph and the total urine excretion after a $40-\mathrm{mg}$. intramuscular injection of gentamicin.

Group 2. Concentration of Gentamicin in Renal Lymph.In six experiments serial 15-minute collections of renal hilar lymph were analysed together with urine and venous blood taken at the midpoint of each collection. The results of these experiments are shown in the Table. There were no significant

Concentration of Gentamicin in Renal Lymph, Thoracic Duct Lymph, and Serum during Hourly Intramuscular Dosage (see text)

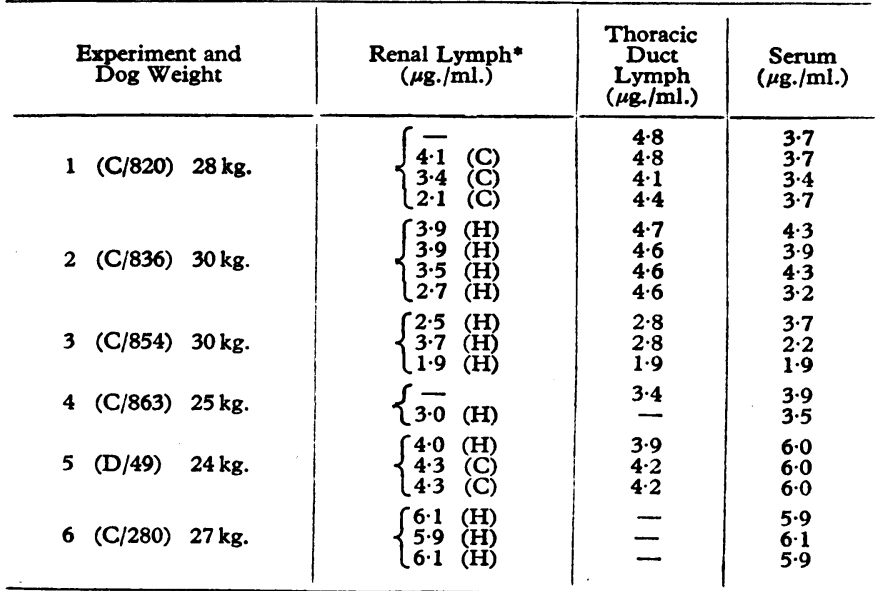

- Each specimen of renal lymph was collected for a 15-minute period; the corresponding specimen of thoracic duct lymph and serum was collected at the $\mathrm{H}=$ Renal hilar lymph.

differences between renal lymph, thoracic duct lymph, and serum concentrations of gentamicin. In two experiments where the lymph was also collected from a renal capsular lymphatic the lymph concentrations were comparable with the renal hilar lymph concentration. In this group of experiments, where the serum gentamicin level was constant, the concentration of gentamicin in the urine varied directly with the rate of flow and ranged from 11 to $350 \mu \mathrm{g} . / \mathrm{ml}$. ; these values were always at least three times the serum and lymph values. Even during a mannitol diuresis the concentration in the urine was always significantly higher than that in serum or lymph. 


\section{Discussion}

Renal lymph is derived from both the renal blood plasma and the reabsorbed tubular fluid (Kaplan et al., 1943), and is thought to represent the interstitial fluid of the renal parenchyma (Katz, 1958). One of the principal functions of the renal lymphatics is to balance intrarenal fluid volumes with flow rates by providing an escape route for increased interstitial fluid, especially in the presence of ureteric obstruction (Goodwin and Kaufman, 1956). The renal lymphatics continue to function even after prolonged ureteric obstruction unless damaged by coexistent pyelonephritis (Babics and Rényi-Vámos, 1964; Chisholm and Calnan, 1967). Thus the concentration of a drug in the lymph from a normal kidney is probably a better indication of its level in the renal parenchyma than any other sampling method at present available.

Since any urinary tract infection may be associated with early pyelonephritis, it is essential that a drug prescribed for this condition does in fact reach the renal parenchyma in therapeutic concentrations (Cockett et al., 1965). The fact that a drug is concentrated in the urine does not imply that the adjacent renal parenchyma has the same or even a similar concentration. Cockett et al. (1965), from data obtained in dogs, showed that the level of nitrofurantoin in the renal lymph was at least double the plasma level, while the urine levels were three to four times the plasma level. They also showed that levels in renal hilar lymph were higher than those from the renal capsular lymph. By contrast, O'Dell and Schlegel (1962) showed that several of the sulphonamides did not concentrate in renal tissue of the rat, despite high blood and urine levels. Nalidixic acid appears to have an affinity for the kidney of the rhesus monkey but not of the dog (McChesney et al., 1964); studies of nalidixic acid concentration in the human pyelonephritic kidney have also shown such an affinity (Jameson, 1965). However, the data in both of these latter reports are based on the analysis of pieces of kidney, and so are liable to error owing to the urinary content of the specimen. It is probable that the parenchymal damage associated with pyelonephritis results in an uneven distribution of any drug, and this may be an important cause of failure of treatment in pyelonephritis.

The concentration of an antibiotic in a single urine specimen may be very misleading in the assessment of its effectiveness. Gentamicin sulphate, the molecular weight of which is $425 \pm 21$ (Rosselet et al., 1963), is excreted almost entirely in its active form by glomerular filtration with little or no tubular reabsorption. The present studies have emphasized how these concentrations may vary with urinary rates of flow-the more pronounced the antidiuresis the higher the gentamicin values. The influence of urinary $\mathrm{pH}$ on the therapeutic efficiency of an antibiotic for urinary infection is well established, and Barber and Waterworth (1966) have demonstrated that gentamicin is 16 times more effective, in vitro, in an alkaline urine. Their data, together with ours, indicate that in order to achieve maximum clinical effect the urine should be both concentrated and alkaline. Our results have also shown that the assay of gentamicin in urine without correction to a constant $\mathrm{pH}$ will be misleading.
The recommended effective clinical dose of an antibiotic is based on in vitro studies to determine the minimum inhibitory concentration in the plasma against a particular organism. The present studies have shown that gentamicin is rapidly and uniformly distributed in lymph from the thoracic duct, in lymph from the kidney, and in the plasma. After approximately two hours the plasma level is representative of the level in the body fluids, and this may be used for therapeutic purposes. The rapidity with which equilibration occurs in the body fluids after an intramuscular injection is matched by the promptness of excretion ; both the plasma and the lymph levels fall pari passu. This rate of excretion has been shown to be dependent on the glomerular filtration rate (Gingell and Waterworth, 1968), so that the maintenance of an effective therapeutic level, especially in the presence of renal impairment, requires control by serial plasma estimations.

\section{Summary}

In an experimental study of the distribution of gentamicin in the body fluids the concentration of this antibiotic was measured in the blood, urine, thoracic duct lymph, and renal lymph. The results showed that the distribution was rapid and uniform throughout the blood and lymph but was concentrated in the urine. The influence of the flow rate and the $\mathrm{pH}$ on the level of gentamicin in the urine is discussed. Since the concentration in the blood is representative of the tissue level throughout the body, effective antibiotic levels will be obtained in the renal parenchyma when gentamicin is used for urinary tract infections.

We are indebted to Professor L. P. Garrod for his helpful comments on this work and to Mr. L. M. Taylor for his technical assistance. We wish to thank the Schering Corporation for a grant to support this project, and for the supply of gentamicin sulphate (Genticin, British Schering Ltd.).

\section{REFERENCES}

Babics, A., and Rényi-Vámos, F. (1964). Clinical and Theoretical Pictures of Some Renal Diseases. Budapest.

Barber, M., and Waterworth, P. M. (1966). Brit. med. F., 1, 203.

Barber, M., and Siter, R. J., Sidell, S., and Kirby, W. M. M. (1963). Ann. intern. Med., 59, 593.

Chisholm, G. D., and Calnan, J. S. (1967). S. Afr. med. F., 41, 978.

Cockett, A. T. K., Moore, R. S., and Kado, R. T. (1965). Brit. ₹. Urol.,

37, 650. $2,1003$.

Gingell, J. C., and Waterworth, P. M. (1968). Brit. med. 7., 2, 19.

Goodwin, W.'E., and Kaufmann, J. J. (1956). Urol. Surv., 6, 452.

Jameson, R. M.'(1965). Brit. med. f., 2, 621.

Jao, R. L., and Jackson, G. G. (1964). Ұ. Amer. med. Ass., 189, 817. Kaplan, A., Freidman, M., and Kruger, H. E. (1943). Amer. F. Physiol., $138,553$.

Katz, Y. J. (1958). Circulat. Res., 6, 452.

Katz, Y. J., Cockett, A. T. K., and Moore, R. S. (1964). Life Sci., 3,

Kleeman, C. R., Hewitt, W. L., and Guze, L. B. (1960). Medicino (Baltimore), 39, 3.

McChesney, E. W., Froelich, E. J., Lesher, G. Y., Crain, A. V. R., and Rosi, D. (1964). Toxicol. appl. Pharmacol., 6, 292.

Mitchison, D. A., and Spicer, C. C. (1949). F. gen. Microbiol., 3, 184. O'Dell, R. M., and Schlegel, J. U. (1962). Fed. Proc., 21, 427f.

Rosselet, J. P., et al. (1963). Antimicrob. Agents \& Chemother., p. 14

Rchlegel, J. U. (1962). f. Ark. med. Soc., 59, 215. 